\title{
Third-Party Ethics in the Age of the Fourth Party ${ }^{*}$
}

\author{
Daniel Rainey $^{* *}$
}

\begin{abstract}
'Third Party Ethics in the Age of the Fourth Party' presents and discusses some of the ethical impacts of the use of information and communication technology (ICT) in third party practice (mediation, facilitation, arbitration, etc.). The article argues that all of the ethical requirements related to third party practice have been affected by the use of ICT, that ethical standards of practice must be reviewed in light of the use of ICT, and that changes in ethical requirements based on the use of ICT will be evolutionary, not revolutionary.
\end{abstract}

Keywords: ODR, ethics, fourth party, ADR, standards of practice.

\section{Introduction: The Influence of the Fourth Party}

At a recent American Bar Association Section of Dispute Resolution Annual Spring Conference, one of the presenters asked a series of questions to his audience regarding the use of online dispute resolution (ODR) technology. ${ }^{1}$ The first question was simple: 'How many of you in the audience currently use online dispute resolution tools?' Of the approximately forty people in the room, only a few raised their hands, and those few were practitioners who were known as longtime advocates of ODR technology. He then asked a series of follow-up questions: 'How many of you use the telephone?' 'Smart phones?' 'Email?' 'Skype?' 'Google Docs or some other document storage in the cloud?' In response to the follow-up questions, most of the hands in the room went up.

More recently, the author posed similar questions to another group involved in the law and alternative dispute resolution (ADR). ${ }^{2}$ In answer to the question

* The term 'Fourth Party' was coined by Ethan Katsh and Janet Rifkin in their 2011 book Online Dispute Resolution: Resolving Conflicts in Cyberspace, cited later in this essay. The Fourth Party refers to technology used in the practice of conflict engagement, and specifically refers to the influence that technology has on the conflict engagement process.

** Clinical Professor of Dispute Resolution at Southern Methodist University, Chief of Staff for the National Mediation Board, and adjunct faculty in the dispute resolution programmes at Creighton University and Dominican University. <http://danielrainey.us〉.

1 ABA Section of Dispute Resolution 15th Annual Spring Conference, Chicago, 3-6 April 2013. The questions were asked by Colin Rule at a session that was part of the Symposium on ADR and the Courts.

2 ABA Section of Labor and Employment Law, Railway and Airline Labor Law Committee, Midwinter Meeting, Coronado, 12-14 March 2014. 
'how many of you use information and communication technology (ICT) in your practice?' every hand went up. When he asked, 'How many of you have thought about the impact technology may have on the ethics of your practice?' only one hand out of sixty went up.

Responses to the presenter's questions make two points that will frame this essay. First, ICT has become an integral part of the practice of conflict engagement in all its forms, just as it has become integral to social interaction generally. Second, most practitioners of ADR in all its forms seem not to have overtly faced the ethical changes and challenges brought with the increased use of ICT.

There is more awareness now than there was just a few years ago. The 'comprehensive guide' to dispute resolution ethics published in 2002 (and still in use today) does not mention technology at all, even though the technology that is now ubiquitous was beginning even then to make inroads into the way we communicate and practise dispute resolution. ${ }^{3}$ The recently published 'advanced' guide for mediators treats technology issues under the heading of 'advanced ethical issues for mediators' ${ }^{4}$

The integration of technology into all kinds of third-party work does not mean that the ethical standards developed for 'traditional' third-party work must be thrown out and rewritten. It does, however, mean that each of the ethical considerations common to third-party work must be reinterpreted in light of the impact of technology. The adjustment in ethical standards will be evolutionary, not revolutionary, and will be accomplished over time through dialogue with practitioners who are facing the new demands, restrictions and freedoms brought to third-party practice by technology. The goal of this article is not to rewrite all of the ethical guidelines, or even to address all of the possible ethical issues raised by the use of ICT. The goal of this article is to point out some concrete instances in which technology affects ethical considerations, and to add to the evolutionary transformation from the assumption of face-to-face processes to the common use of processes integrating ICT.

The international, or a-national, nature of communication and interaction produced in the online world confronts practitioners of all kinds with challenges that are new.

One important practical effect of globalization [fueled by the use of ICT] is that clients regularly expect [practitioners] to handle matters that involve multiple jurisdictions, domestic and international. [...] [not] contained by national borders. [... $]^{5}$

The borderless nature of virtual interactions guarantees that those involved in conflict engagement will encounter work that involves customs, cultures, expectations and demands that are heterogenous in nature.

3 P. Bernard \& B. Garth (Eds.), Dispute Resolution Ethics: A Comprehensive Guide, ABA Section of Dispute Resolution, Washington, DC, 2002.

4 S.N. Exon, Advanced Guide for Mediators, LexisNexis, 2014, Chapter 7.

5 J. Podgers, 'Closing Act', ABA Journal, January 2013, p. 21. 
A Google search on the phrase 'how social media has changed us' yields $536,000,000$ hits. $^{6}$ Some people (perhaps a half a billion of us) seem to think that social media has made a change in the way we interact. It is common to hear the argument that technology isolates us and drives us apart. But an equally, if not more, persuasive argument is that technology brings us together in different ways.

Lee Rainie and Barry Wellman argue that, like earlier communications technology (the telephone, television, etc.), ICT has brought us closer and has changed, not eliminated, our social interaction. As they argue:

[...] we wonder about the folks who keep moaning that the Internet is killing society. They sound just like those who worried generations ago that TV or automobiles would kill sociability, or sixteenth-century fears that the printing press would lead to information overload. [...] none of these technologies are isolated - or isolating - systems. They are being incorporated into people's lives much like their predecessors were. People are not hooked on gadgets - they are hooked on each other. ${ }^{7}$

In the mid-1990s, some ADR practitioners realized that the emerging online communication channels were having an impact, mostly in the commercial arena. They coined the term 'Online Dispute Resolution (ODR)' to describe and differentiate what they were seeing as a new venue for dispute resolution. ${ }^{8}$

The classic definition of ODR comes from those early days of e-commerce. When the U.S. National Science Foundation (NSF) lifted the ban on commerce online in 1992, there quickly began to appear disputes unlike disputes we had created before: disputes with parties in far-flung geographic locations, engaging in conflict created online with no reasonable ability to pursue resolution in traditional ADR or legal channels.

Into this new conflict environment came a number of ODR tools designed to handle the high volume of disputes with as little human intervention as possible. We are now at a point, 22 years later, at which eBay, the poster child for ODR, is handling over 60 million disputes per year, $90 \%$ of which are handled with no human intervention, and in which the American Arbitration Association (AAA) has announced a partnership with an ODR provider to handle as many as 100,000 arbitrations per year in New York state alone. ${ }^{9}$

By 2001, Katsh and Rifkin were able to observe the rise of online commerce and the rise of technology to address the disputes created in online commerce,

6 Search results on Google, 25 March 2014.

7 L. Rainie \& B. Wellman, Networked: The New Social Operating System, MIT Press, Cambridge, 2012, p. 6.

8 See E. Katsh, 'ODR a Look at History', in M.S. Abdel Wahab, E. Katsh \& D. Rainey (Eds.), Online Dispute Resolution Theory and Practice: A Treatise on Technology and Dispute Resolution, Eleven International Publishers, The Hague, 2012.

9 In March 2014, the AAA and Modria announced their relationship. To see the basic information related to Modria's arbitration work with the AAA, go to this URL: <www.modria.com/newsroom/american-arbitration-association-selects-modria-power-new-york-fault-caseload/> . 
and to describe the technology that was being used to handle conflict online as the 'fourth party'. ${ }^{10}$ The fourth party as an active participant in the dispute resolution process is still very much alive and kicking, as witnessed by the eBay and AAA statistics cited above.

As time has passed and ICT has burrowed its way into the fabric of society far beyond e-commerce, another more contemporary and nuanced definition of ODR and of the fourth party has emerged. That definition of ODR, the one used throughout this article, is that ODR is simply the intelligent application of ICT to any of the processes that make up the universe of conflict engagement practice.

Why has ICT become a routine element of conflict engagement practice? At least in part, it is because some of the basic functions or activities of conflict engagement practitioners are basic functions or capabilities at the core of ICT. At a very general level, conflict engagement efforts require that practitioners engage in three basic activities, whether those activities occur 'at the table' with divorcing couples or in dispersed locations involving multiple groups.

Conflict engagement requires that we: (1) facilitate communication among the parties, (2) assist in the handling of information and data and (3) manage group dynamics. ICT: (1) opens new communication channels, (2) offers new ways to handle information and (3) creates new ways to manage group dynamics (and even allows the practitioner to redefine 'group').

If three of the core functions of conflict engagement are also three of the core innovations of ICT, how could dispute resolution not be changed by the ubiquitous nature of ICT in the contemporary world? As we operate in this wired/ wireless world, the influence of the 'fourth party' goes far beyond the algorithmdriven programmes used in e-commerce and the artificial intelligence programmes that are being used to 'build a better mediator'. The fourth-party influence can rightly be seen any time a third party uses technology to communicate with or share information with the parties. And every time technology, the fourth party, enters the process, there are ethical issues either raised or altered.

\section{Technology and the Ethics of Conflict Engagement}

What are the standards of practice that govern ODR? If one takes as a starting point the idea that technology has been integrated into the entire range of practice in ADR, it would seem reasonable to argue that any of the ethical standards that apply to the practice of conflict engagement must be interpreted in the light of the impact of technology - to account, in other words, for the fourth party.

There are many ongoing discussions of ethics as they relate generally to the practice of conflict engagement. ${ }^{11}$ For purposes of this article, standards of prac-

10 See E. Katsh \& J. Rifkin, Online Dispute Resolution: Resolving Conflicts in Cyberspace, Jossey-Bass, San Francisco, 2001. See, particularly, 'Introducing the Fourth Party: The Critical Role of Technology', p. 93 et seq.

11 For example, see L. Kriesberg, 'Moral Judgements, Human Needs and Conflict Resolution: An Alternative Approach to Ethical Standards', in K. Avruch \& C. Mitchell (Eds.), Conflict Resolution and Human Needs: Linking Theory and Practice, Routledge, New York, 2013, p. 77. 
tice and ethical guidelines created for mediation will serve as the basis for discussion of ethical considerations generally. It is convenient, and perhaps necessary, to use mediation as a focus for at least two reasons.

First, mediation offers a base of theory and practice that is reflected in many other conflict engagement venues. At all levels and in all venues, practitioners engage with human beings interacting in stressful and, perhaps, dangerous situations. Ellen Waldman offers three core values that drive mediation ethics: disputant autonomy, procedural fairness and substantive fairness. ${ }^{12}$ At the most general level, these values would probably be accepted by practitioners in most venues.

Second, much has been written about mediator ethics. The range of ethical statements or standards of practice for mediation make up a large part of the literature on ethics and third-party practice. ${ }^{13}$ This article will refer to standards of practice statements and/or ethical standards from a cross-section of organizations dealing with conflict engagement issues, including the AAA, the American Bar Association (ABA), the Association for Conflict Resolution (ACR), the Judicial Arbitration and Mediation Services (JAMS) and two state organizations, from Virginia and Texas, where the author regularly works. ${ }^{14}$

\section{The Standards and their Relationship to Technology}

As a note to start this discussion of the impact of technology on standards of practice, all of the traditional requirements expressed by the various statements remain untouched by the use of technology. For example, the need to be and remain free from favouritism, bias or prejudice remains just as essential for an

12 See E. Waldman, Mediation Ethics: Cases and Commentaries, Jossey-Bass, San Francisco, 2011.

13 Some discussions of ethics address the relationship between mediation and the formal justice system, and indeed the concept of justice itself. See A. Wellington, 'Professional Ethics for Mediators: Tensions Between Justice and Accountability', Social Philosophy Today, Vol. 17, 2001, pp. 125-150. Some compare standards of practice, assessing similarities and differences. See S. McCorkle, 'The Murky World of Mediation Ethics: Neutrality, Impartiality, and Conflict of Interest in State Codes of Conduct', Conflict Resolution Quarterly, Vol. 23, No. 2, 2005, pp. 165-183. The continuing friction between mediator ethics and legal ethics is an ongoing subject. See A.C. Yang, 'Ethics Codes for Mediator Conduct: Necessary But Still Insufficient', Journal of Legal Ethics, Vol. 22, 2009, p. 1229. Wilson's recent essay takes the ethics discussion back to basic texts that have helped define the field of conflict resolution: B. Wilson, 'Mediation Ethics: An Exploration of Four Seminal Texts', Journal of Conflict Resolution, 2011, p. 119.

14 The AAA standards can be found at: <www.adr.org/aaa/ShowProperty?nodeId=\%2FUCM \%2FADRSTG_0104098\&revision=latestreleased $\rangle$.

The ABA standards can be found at: <www.americanbar.org/groups/professional_responsibility/publications/model_rules_of_professional_conduct/model_rules_of_professional_conduct_table_of_contents.html>.

The ACR standards for Family and Divorce mediation can be found at: <www.acrnet.org/ Page.aspx?id=633>.

The JAMS standards can be found at: <www.jamsadr.com/mediators-ethics/>.

The Virginia standards can be found at: <www.courts.state.va.us/courtadmin/aoc/djs/programs/drs/mediation/soe.pdf >.

The Texas standards can be found at: <www.txmca.org/ethics.htm>. 
all-online ODR process, or a mixed ODR and face-to-face process as it does for an all-face-to-face process. Essentially, the mediator, or any third party in any intervention venue, faces the same problems, the same choices and the same requirements for practice whether or not technology is introduced.

Put another way, the questions facing third parties remain the same, although the answers may change a bit on the basis of the additional elements added by the use of technology. In recognition of this, the ABA Ethics 20/20 Commission report suggests that questions relating to technology and ethics should continue to be addressed in an ongoing manner as '[...] virtual practice becomes clearer and as relevant technology continues to evolve'. ${ }^{15}$

Part of the evolutionary progress of technology involves the development of technology that is specifically designed for use in the practice of conflict engagement. Up to the present, much if not most, of the work done using technology has employed applications and platforms designed for more general communication or information-handling purposes. For example, commercial products like WebEx or Central Desktop were developed to enhance group work and communication across geographically dispersed groups in synchronous and asynchronous modes. These platforms are easily adapted to conflict engagement work. ${ }^{16}$

There have been platforms designed specifically for conflict engagement work, but they have either tended to be proprietary in nature (e.g. eBay's internal system) or have not been able to attract a sufficient number of users to maintain commercial viability. That is beginning to change, ${ }^{17}$ but it is still the case that most technology used by practitioners has been designed for more general online group work. In either case, the use of ICT provides the impetus for the 'evolution' of practitioner ethics.

This article will focus specifically on a few of the ethical imperatives that, through conversations with a wide range of conflict engagement practitioners, seem to be most obviously and immediately affected by technology.

\subsection{Confidentiality}

Practitioners and parties alike look to the third party's right to maintain confidentiality, and his or her ability to maintain confidentiality, as a cornerstone of the intervention process. The reliance on confidentiality allows for free expression of ideas and options that, for many reasons, might not surface in a proceeding where the exchanges become part of the public record or may be used as evidence of 'intent'.

ABA Ethics 20/20 Report, p. 10. Available for download at: <www.americanbar.org/content/ dam/aba/administrative/ethics_2020/20121112_ethics_20_20_overarching_report_final_ with_disclaimer.authcheckdam.pdf $>$.

16 The U.S. National Mediation Board has used WebEx to conduct online arbitration and online mediation synchronously, and Central Desktop to provide asynchronous platforms for complex collective bargaining.

17 For example, the agreement between Modria and the AAA features a 'bespoke' dispute resolution platform. 
The actual right to maintain confidentiality is expressed, on the basis of venue, by state statutes and guidelines, ${ }^{18}$ and by federal guidelines, ${ }^{19}$ and it is incumbent on the mediator to know what rules apply to the mediation he or she is conducting in a specific venue. ${ }^{20}$

The JAMS confidentiality standard states:

It is crucial that the mediator and all parties have a clear understanding as to confidentiality before the mediation begins. Before a mediation session begins, a mediator should explain to all parties (a) any applicable laws, rules or agreements prohibiting disclosure in subsequent legal proceedings of offer and statements made and documents produced during the session, and (b) the mediator's role in maintaining confidences within the mediation and as to third parties. ${ }^{21}$

The requirement for the mediator to know, understand and communicate the elements of confidentiality and information safety online exists when technology becomes part of the process.

The most common first question about ethics and technology seems to be 'How do I, as a mediator, maintain confidentiality and the security of party information?' A second and equally important question should be 'How do I describe the right of confidentiality and the actual safety of their information in an online environment accurately, and in a way that allows for the parties to make an informed choice about whether to consent to online work?'

First, there are questions about what our general responsibility and capability is regarding confidentiality. We have a hard enough time in the face-to-face world explaining under what conditions mediators can assert confidentiality, but adding technology does not really change any of the conditions of confidentiality.

If, in a process labelled mediation, a party says something to a mediator in a caucus, out of the hearing/sight of the other party, it is likely that the mediator can assert the right to confidentiality. That, it is assumed, holds true for statements made (orally or in writing/text) in private or caucus sessions online. In theory, it may be possible to argue that the very act of passing the information over an online communication channel is 'publication'. To date, this argument has not surfaced, but because it is theoretically possible to make the argument, it and other arguments related to the special nature of discourse online will probably be made by someone at some point.

Outside the actions of the parties themselves, and the third party who has made the promise of confidentiality, there are fourth-party considerations that loom large. There is reasonably long-standing guidance regarding the use of off-

18 See, e.g., Maryland Senate Bill 859, 'Maryland Mediation Confidentiality Act', at <www.courts.state.md.us/macro/pdfs/mmcach309sb0856e.pdf〉.

19 See Alternative Dispute Resolution Act of 1998 (28 USC §652).

20 For a brief discussion of confidentiality and a recent Federal Court decision on mediator confidentiality, see S. Leasure, 'Mediation Confidentiality Rules Have Teeth', Eminent Domain ADR, 8 June 2012, at <http://blog.edom-adr.com/?p=800\#_ftn1〉.

21 JAMS, Standard IV. 
line paper and electronic information storage managed by contractors. There is a growing body of guidance related to online storage of information. The New York State Bar says that:

An attorney may use an online storage system, provided the attorney exercises reasonable care to ensure that confidential information will remain secure. $^{22}$

The problem for third parties, once again, is that translating guidance for offline systems to guidance for online systems is not automatic.

While it may be clear what constitutes reasonable care in the context of traditional third party storage, these same practices do not seamlessly transfer to online storage. ${ }^{23}$

The second set of questions has to do with the safety of information passed through online channels, regardless of whether the information was offered publicly (e.g., in a mediation session with all parties present) or privately (e.g. just to the mediator in a caucus 'room' online). Not to belabour the point, the questions tend to be something like 'how likely is it that my information will be 'hacked' and stolen by someone?'

Before addressing that question from an ethical point of view, how likely is it, generally, that private information will remain private once it is exchanged online?

The answer is complicated. Before the public revelation of the extent of digital surveillance conducted by the United States and other countries, the common answer would have been that your information could be considered fairly secure. The revelations of and the notoriety gained by Edward Snowden, and the extent of the government surveillance he exposed, have made it more difficult for the general public to believe in the privacy of information exchanged online. Following close on the heels of the Snowden information, the publicity surrounding the compromised personal information contained on the U.S. retailer Target's servers during the past Christmas shopping season did nothing to increase general confidence in the safety of online information.

From an ethical viewpoint, the third party is faced with two responsibilities: to understand the risks and to communicate the risks realistically to the parties. It may be, in fact, highly unlikely that information exchanged during conflict engagement work online will be compromised, but the devil really is in the details, and is linked to the type of online system being used.

Email is the worst form of online communication that is least secure, easiest to accidentally misuse and most likely to be 'hacked'. Basically, no mediator or party should use it for anything they would not be willing to see on the front page

22 New York State Bar Association Committee on Professional Ethics, Opinion No. 842, 2010.

23 ABA Section of Labor and Employment Law Ethics Flash: available at <www.americanbar.org/ newsletter/groups/labor_law/1l_flash/1105_aball_flash/1105_aball_flash_ethics.html>. 
of the local newspaper. For confirmation of this, just ask any public figure whose 'private' email messages have wound up in the public media. ${ }^{24}$

Cloud applications such as Google Docs, Google Drive or the Amazon cloud space offer open applications and data storage, which generally means that your data is mixed in with other people's data. But you can password-protect your information, and you can control who sees it, and organizations like Google have a built-in incentive to make sure your information is not misused or stolen.

Of course, anyone at Google with Admin rights can get to information on their servers, but, again, they have a built-in incentive to be very careful with that ability. At one point, the fact that information moved to and from Google servers was encrypted was a comfort to users. The revelation that the National Security Agency (NSA) had found a way to grab information between encryption processes brought a reasonable level of concern to even the safety of encryption.

What could be called 'bounded cloud' applications may be, arguably, safer. Commercial, bounded cloud applications treat information in a way that further separates 'your' data from the rest of the world. ${ }^{25}$ The information put into a bounded cloud is on servers used only by paying customers, and is generally SSLencrypted in addition to being password-protected. Still, the administrators of the bounded cloud systems have access to the data, and are constrained by the same business incentives as any administrators working in systems reliant on the trust of their customer base.

So how does the third party reasonably describe the online world in terms of data security and client confidentiality? First, it is incumbent upon every mediator who wants to use online tools to educate himself or herself about the realistic risks that parties take when they work online. As a matter of ethics, mediators should understand how the technology works on at least a basic level, and should make choices about what technology they recommend for use on the basis of that knowledge.

Second, mediators should carefully consider how to describe the risks to the parties. There are always some risks, even with paper documents, and parties will always have to make choices about what venues and channels they are willing to use. The responsibility of the mediator is to describe the risks and benefits in a way that allows for a truly informed decision by the parties.

As a final note on confidentiality and information safety, all of the egregious breaches of confidentiality and security the author has witnessed as a mediator came as a result of parties copying and passing around paper they should have not shared, not from hacking or losing information online.

24 Not all email systems are created equal. Some are encrypted, some are not. Some are well protected, some are not. Generally, email systems are more vulnerable than data storage applications and are among the first targets of those trying to break into online systems.

25 There are numerous examples of bounded cloud environments. SydneyPlus built its reputation by handling data for law firms and building online libraries <http://sydneyplus.blogspot.com/ > CentralDesktop is one of many 'group work' sites that offer appealing features for ODR use, and offer a high level of security <www.centraldesktop.com/>. Modria.com offers software designed for dispute resolution, with data resident on its servers in a protected environment < www.modria.com/>. 


\subsection{Self-Determination}

The mandate for self-determination is at the centre of the practice of mediation. Under the headings of self-determination and impartiality, the AAA/ABA/ACR and JAMS Model Standards require that:

[...] A mediator should endeavor to provide a procedurally fair process in which each party is given an adequate opportunity to participate. ${ }^{26}$

A mediator shall conduct a mediation based on the principle of party selfdetermination. Self-determination is the act of coming to a voluntary, uncoerced decision in which each party makes free and informed choices as to process and outcome. Parties may exercise self-determination at any stage of a mediation, including mediator selection, process design, participation in or withdrawal from the process, and outcomes. ${ }^{27}$

If we take as given that technology is now an integral part of the ADR world, the standard probably should state:

Parties may exercise self-determination at any stage of a mediation, including mediator selection, platform selection, process design, $[\ldots]^{28}$

In face-to-face practice, third parties have developed many strategies to ensure that parties have access to the process, have input into the 'ground rules' that govern sessions and have a high degree of ownership in the process to which they agree. What impact does the use of ICT have on the concept of selfdetermination?

A common issue with which the author often has been confronted has to do with the role of the third party's comfort with technology. In short, is the fact that the third party is partial to certain online tools unduly influencing him or her to push the parties to use those online tools? The analogue to this issue in faceto-face work can surface when the third party is challenged to adapt his or her process to fit the comfort zone of the parties.

How much should a third party 'flex' his or her process? If the process mode is mediation, most third parties enter the process inclined to frame issues, discuss interests, develop options and discuss options in an attempt to craft a resolution. Generally, the approach is to do the work together, speaking in turn, in an environment where the third party has attempted to 'level the playing field'. What if one of the parties is uncomfortable with a level playing field? What if the party is acutely conscious of and wants to acknowledge the power imbalance as part of everyday life outside of mediation? Traditional ethical guidelines suggest that the third party should at least consider a process whereby the power imbalance is considered and integrated into the session. Failing that, ethical guidelines suggest 
that at least the third party should not insist on running the session his or her way in the face of obvious discomfort on the part of the parties themselves.

In a process that may involve ICT, the ethical imperatives involve attention to the parties' preferences and comfort levels in relation to the use of technology. In short, the third party needs to be sure that both parties are equally willing to use whatever online tools (or ICT tools offline) are available, and that they have reasonably equal facility to use those tools. And, turning the lens in the other direction, there may be a higher comfort level with technology among the parties than with the third party. Is there an ethical issue involved with dissuading parties to use communication channels with which they are comfortable, but in which the third party has no faith?

A recent iteration of an old argument has been made, asserting that 'cyber mediation cannot work'. ${ }^{29}$ It is a continuation of an argument that has accompanied the development of ODR since the earliest incursion of technology into traditional practice. Leaving aside observations that 'cyber mediation' is working and has been working for some time, and that other 'cyber interventions' have been found equally practical, what is the ethical imperative for a third party who accepts the 'cannot work' view of ODR? If the parties would be comfortable using ICT in all or part of the process, and if the use of ICT would advantage them in terms of cost, or convenience or safety, would the third party's refusal to use ICT be unethical?

Generally, this question has to do with the parties' expressed preferences (for all face-to-face work or for some use of technology), and perhaps involves the classic issue of computer literacy. At one time, not too many years ago, computer literacy was the number one response on informal surveys about barriers to the use of ODR technology. ${ }^{30}$ As online communication has become more and more a regular part of the everyday lives of a majority of people, with grandparents and great-grandparents using Skype and FaceTime to 'visit' with the grandkids, the issue of computer literacy has been replaced by the loss of non-verbal as the most often expressed barrier to the use of technology.

But computer literacy is still an ethical issue for mediators. One organization devoted to teaching computer literacy defines it in terms of user facility:

Computer literacy is the knowledge and ability to use computers and technology efficiently. [...] The highest goal of a computer-literate person is to be

29 B.A. Friedman, 'Online Mediation - Press Delete?', posted in the ABA Section of Dispute Resolution Linked In Discussion Group, 9 September 2013, available at: <http://friedmanmediation.com/mediation/online-mediation-press-delete-2/>.

30 The author regularly teaches ODR courses for universities and community mediation centres, and at the beginning of each course he polls the students on their perceptions of the barriers and advantages inherent in the use of ODR technology. For many years the top answer was 'computer literacy', followed closely by 'loss of non-verbal'. The non-verbal response remains at the top of the list, but computer literacy has fallen off almost altogether. For a brief discussion of this and other issues in the teaching of ODR methods, see: D. Rainey, 'Teaching Online Dispute Resolution: Results from a Survey of Students', via Mediate.com, at <www.mediate.com/articles/ RaineyD1.cfm>. 
able to learn and use new computer programs without large amounts of help. ${ }^{31}$

The phrase 'without large amounts of help' is key to the dilemma facing the mediator. Put simply, every minute the mediator has to spend paying attention to managing and learning the technology, the less time he or she has to focus on the parties and their problem. The more the parties have to focus on using the technology, the less effective they may be in addressing their problem. The ethical imperative here is to choose technology wisely, describe it to the parties realistically, prepare them to use the technology and monitor their use for signs that one party or another may be having problems or may be disadvantaged through the use of a particular platform. Although most of the available online tools are very simple and can be picked up and used by parties with very little in the way of training, there is still a need for the mediator to create an environment in which the parties feel treated fairly, and in which they do not feel that the process itself is negatively influencing a possible outcome.

There are a number of ways in which third parties have dealt with these issues. Where possible, having a private conversation with each party before beginning mediation gives the mediator the ability to talk with the parties about their comfort level, their computer literacy and their interest in using ICT as part of the mediation process. Usually it is possible to get a very good idea about the comfort level and the computer literacy from a short conversation, and it is possible to determine whether the use of technology is a subject that would be comfortable for both parties to discuss together with the mediator.

Best practices in ODR would suggest that the mediator conduct some training for the parties before beginning any use of ICT with their issue(s). Training need not be formal training. In fact, for the author most often this training takes the form of an exercise that has no risk, but which has the parties using all of the functions of the ICT tools they will see in the mediation process.

For example, to 'train' parties in the use of online brainstorming tools and rating and ranking tools, the mediator can have them go through a short exercise naming and ranking the greatest rock and roll songs of all time, or the best movies of all time or some such topic. By having a little fun and using the technology, the parties become familiar with all of the functions and can use it for real issues without having to figure it out as they go along. ${ }^{32}$ After the low-risk exercises, it is possible to do a second round of discussions with the parties to make sure everyone is still comfortable using the technology for the mediation, and on the basis of the follow-up discussions, it is possible to default to a face-to-face process or to use a more friendly technology.

In terms of accessibility, ODR platforms face issues beyond basic access to the Internet or to specific platforms. The need to adapt to language barriers, hearing

31 Technology Fluency Institute, at <www.techfluency.org/computer-literacy.htm>.

32 The author is quite aware that 'having fun' together is not possible for many parties, but it is usually possible to craft some kind of low-risk use of the technology before beginning to work on the hard issues. 
impairment, vision impairment etc. remain, but the manner in which they may be dealt with changes with the introduction of the variety of text, audio and video communication channels available for ODR.

Finally, it is necessary to monitor the parties' use of the platform during whatever conflict engagement process is underway. If one party is perceived to be participating less or having some trouble with the platform, the third party can do a process check and perhaps abandon or adjust the technology at that point.

Again, the basic ethical responsibility of the mediator as it relates to impartiality and self-determination is to make sure that the process is open to input from the parties, to make sure that neither of the parties is disadvantaged by use of technology and to make sure that the mediator's own preferences are not being pushed on the parties. It is obviously the case that one of the reasons parties come to third parties is to get advice on process and to have an expert help them manage discussions about difficult topics. In that context, suggesting online technology is perfectly acceptable, and in fact may be a preferable option as long as the mediator does not cross the line to using or not using technology as purely personal preference.

\subsection{Mediator Competence 33}

A mediator should have sufficient knowledge of relevant procedural and substantive issues to be effective. ${ }^{34} \mathrm{~A}$ mediator should attend educational programs and related activities to maintain and enhance the mediator's knowledge and skills related to mediation. A mediator should have available for the parties information relevant to the mediator's training, education, experience and approach to conducting a mediation. ${ }^{35}$

This is an interesting and thorny question, both with technology and sans technology. There is a pretty sad history of debate among mediators and other third parties about credentials, accreditation and competence, the upshot of which is that it is possible to hang out one's shingle and declare competency as a mediator with no mandatory training or preparation.

In the United States, if a mediator works with court-referred systems or with other special venues, it is likely that he or she will have to complete a forty-hour skills course, which may or may not be recognized in another jurisdiction. In this specific court-related context, a graduate degree in dispute resolution carries no more weight than a forty-hour course as far as formal credentialing goes. In fact, in most court-referred venues, a dispute resolution degree, de facto, carries less weight than a forty-hour skills course. The issue of licensing or accrediting mediators and other third parties is one that has been debated from the earliest days of the ADR movement. The title of a panel discussion at a recent dispute resolution ter.

35 Model Standards, Standard IV: Competence. 
conference succinctly states one polar position: 'Cosmetologists are Licensed: Why Aren't Mediators?'36 The other polar position is that creativity in the approach to the mediation process would be negatively affected by having one standard for licensing or accrediting. Whatever the merits of either argument, the current state of affairs is that there are several measures of competence, none of which adequately address the issue of technology and third-party ethics.

As a practical matter, how do we ask the self-reflective question 'Am I competent to engage in this enterprise?' Most of us recognize the need to engage in formal training, work with lead mediators, co-mediators or mentors, and to work at maintaining currency regarding developments in the world of dispute resolution. But where do you go to become 'competent' to use ODR technology? Most training programmes do not offer any ODR training, and most formal degree programmes either do not address ODR or address it in one semi-skills, semi-theory course. The ethical imperative here is to search out ways to learn from those who have engaged in the use of ODR technology over a period of time, to devote time and energy to working with technology away from parties and to do one's best to really become competent. In the broadest sense, most of the questions that we ask about the use of technology and the problems we raise in the use of technology are the same problems that we see and discuss in face-to-face environments - we just face them in new communication channels and with new ways of dealing with information.

Second, there is an ethical element to the way we describe to potential parties the areas in which we are 'expert'. We can use formal training and education as a measure of our expertise - 'I have completed my State Supreme Court's approved 40-hour mediator training', or 'I have a degree in Dispute Resolution from a reputable university'. I am not sure either would prove competence, but certainly either could be a publicly declared element of competence. We can use experience as a measure - 'I've done a thousand mediations in the last year'. Of course, we could have done a thousand mediations badly, but volume is some measure of competence. We could use associations with acknowledged experts - 'I've studied and worked with Mediator X, one of the masters of online dispute resolution'.

Ultimately, mediator competency is tied closely to creation of trust - trust that the parties place in the mediator - and, to a great degree, trust is generated by the ability of the mediator to demonstrate knowledge. So we come back to the ethical requirement that the mediator conscientiously engage in selfdevelopment related to the use of technology before presenting to the public a declaration of competency.

As ICT continues to insinuate itself into the everyday lives of people in all walks of life, in all locations, the challenge for third parties is to seek opportunities to learn from colleagues, and to teach colleagues, in subjects related to ODR. A recent survey of the responsibilities of third parties to understand and address issues arising from the use of ICT suggests that: 
While advances in technology and communications may leave an attorney scratching his or her head as to the application of the ethics rules, this need not be the case. The essence of the ethics rules remains unchanged. By applying common sense and remembering that the rules do not cease to apply simply because technology is involved, an attorney can tackle the challenges of practicing law in the 21 st Century with confidence. ${ }^{37}$

This approach is probably overly optimistic. It is more likely that we will, as a field of practice, need to develop specific standards of knowledge and measures of competence that go beyond 'common sense'.

\subsection{Quality of Process and Withdrawal}

A mediator shall conduct a mediation in a manner that promotes diligence, timeliness, safety, procedural fairness, and mutual respect among all the participants. $[\ldots]^{38}$

[...] a mediator should be aware of the potential need to withdraw from the case if procedural or substantive unfairness appears to have undermined the integrity of the mediation process. ${ }^{39}$

The ethical requirement to end a mediation if there is 'gross inequality' or 'substantive unfairness' is the same for online and offline work. The difference introduced by the use of technology centres on the need for the mediator to monitor the parties' participation for signs that, informed consent notwithstanding, one party or the other seems to be disadvantaged by the use of technology. Seeing this possibility, it would seem reasonable for the mediator to pause the proceedings, caucus with the parties, and make a decision about whether and how to continue in a way that is acceptable to both parties and that guarantees 'procedural fairness'.

Issues involving conflicts of interest differ a bit between lawyer mediators and non-lawyer mediators, primarily in that there are formal and enforceable standards for what constitutes a conflict of interest for lawyer mediators, whereas there are only guidelines for non-lawyer mediators. The existence of social media and the ability to 'associate' with someone in a virtual manner has complicated the issue of conflict of interest. The formal and enforceable standards used by various state bars help lawyer mediators a bit, but are clearly still in a state of evolutionary development and are not consistent across jurisdictions.

37 C.E. Greene, 'Do Lawyers Have an Ethical Duty to Understand Technology?', American Bar Association Section of Labor \& Employment Law National Symposium on Technology and Labor and Employment Law, Co-sponsored by the UC Berkeley Center for Labor Research and Education and the Berkeley Center for Law and Technology, 21-23 April 2013, p. 19.

38 Standards of Ethics and Professional Responsibility for Certified Mediators, Office of the Executive Secretary of the Supreme Court of Virginia, 1 July 2011, Standard K: Quality of the Process.

39 JAMS Guidelines, Standard VII: A Mediator Should Withdraw Under Certain Circumstances. 
The ability to 'friend' is a case in point. Narrowing the issue to the relationship between judges and lawyers, there are three basic questions that model standards of conduct address. Three different state bars offer seemingly contradictory, or at least partially contradictory, guidance.

First, can a judge be a member of a social media community? Florida rules suggest 'maybe', depending upon who the 'friends' are. California standards also offer a qualified 'yes', as do the standards from Kentucky.

Second, can judges be 'friends' with lawyers who may at some point appear before them? Florida rules say 'no'. California and Kentucky guidance offer a qualified 'yes'.

Third, can a judge be a 'friend' with a lawyer who is currently appearing in the judge's court? Florida and California both firmly say 'no'. Kentucky rules offer a qualified 'yes'.

Some ethical issues are left untouched by any of the guidelines. If a judge friends a lawyer who then moves into practice in the judge's jurisdiction, does 'un-friending' constitute enough to keep from causing ethical problems? If a judge 'friends' a lawyer who at some point appears before the judge, is 'un-friending' enough to stave off the need for recusal? ${ }^{40}$

These questions are asked in the context of formal standards of conduct that can be enforced for lawyers, but the same kinds of questions can be asked of nonlawyer mediators and third parties: is an online social relationship with any party enough to suggest that the mediator should withdraw from a case? Certainly in the eyes of some parties 'friending' could create a perception of bias that would be hard to overcome.

\subsection{ODR Tools in General Practice}

The focus of this article has been a few of the many ethical considerations created when new communication channels, new ways to handle information and new ways to conceive of group work are created by the growth of ODR platforms and ICT platforms adaptable to ODR work. Especially in the legal profession, there is also a growing body of commentary and action related to the use of ICT by practitioners.

Is it, for example, a violation of the Model Rules of Professional Conduct if someone endorses an attorney on LinkedIn when that person has not been directly in a client relationship with the attorney? Is it ethically questionable for a mediator, whether a lawyer or not, to have endorsements on a LinkedIn site from friends and colleagues who may have clicked 'yes' on the 'Does X have these skills or expertise?' without the prior knowledge of the lawyer/mediator? This is, currently, an unsettled issue. Michael Downy, a litigator speaking from the point of view of an attorney, suggests that 'the Internet remains the newest ethical frontier', and that 'This is, in a way, still like the Wild West'. ${ }^{41}$

40 See Domville v. Florida - 103 So. 3D 184 (Florida 4th DCA), 2012; California Judges Association Formal Opinion No. 66, 2009; Kentucky Judicial Ethics Opinion JE-119, 2012.

41 In A.W. Lasker, 'LawPulse: Lawyers and LinkedIn Endorsements', Illinois Bar Law Journal, Vol. 101, No. 1, 2013, p. 10. 
How does one present oneself as 'competent' on websites and social media sites? The Model says:

A mediator shall be truthful and not misleading when advertising, soliciting or otherwise communicating the mediator's qualifications, experience, services, and feed. A mediator should not include any promises as to outcome in communications, including business cards, stationery, or computer-based communications. A mediator should only claim to meet the mediator qualifications of a governmental entity or private organization if that entity or organization has a recognized procedure for qualifying mediators and it grants such status to the mediator. ${ }^{42}$

In any transitional period there will be a tendency to apply existing rules, created and refined in one environment, to the new environment. One example is the application of legal advertising limits to the use of online communication and social media. A suit by a Florida firm ${ }^{43}$ seeks to overturn rules limiting the use of the Web and social media, arguing that applying advertising rules to Internet communication amounts to making 'it effectively impossible for Florida lawyers to write blogs, publish their results in past cases, or to participate in social media sites like LinkedIn'. ${ }^{44}$ Non-lawyer mediators do not face the same level of oversight or restrictions, but it is imperative that, as a profession, those who engage in conflict engagement of all kinds discuss how and in what way online communication channels may be used ethically. As attorney Steve Mason noted, 'Times have changed, and technology has changed everything. ${ }^{45}$

Another area in which the boundary between the legal ADR world and the rest of the conflict engagement world may be affected by technology is the area involving the practice of law.

A mediator should ensure that the parties understand that the mediator's role is that of neutral intermediary, not that of representative of or advocate for any party. A mediator should not offer legal advice to a party. [...] If a mediator assists in the preparation of a settlement agreement and if counsel for any party is not present, the mediator should advise each unrepresented party to have the agreement independently reviewed by counsel prior to executing it. [...] A mediator should make an effort to keep abreast of developments within the mediator's jurisdiction concerning what constitutes the practice of law. ${ }^{46}$

As one possible wrinkle introduced by technology, does the production of a merged set of bullet points into a draft text document by the mediator constitute 
the drafting of a contract? Is that offering counsel? Is that ethically forbidden? These issues, added to the debate over lawyers engaging in non-law practices, and non-lawyers investing in law practices, will continue to be a source of ethical dialogue.

Most parties would not consider the use of a third party's office or meeting room, which comes at an overhead cost to the third party, as a conflict of interest. But is it a conflict of interest to invest in an ODR platform and then channel clients towards using that platform? The Model Standards indicate that:

A mediator shall avoid a conflict of interest or the appearance of a conflict of interest during and after a mediation. A conflict of interest can arise from involvement by a mediator with the subject matter of the dispute or from any relationship between a mediator and any mediation participant, whether past or present, personal or professional, that reasonably raises a question of a mediator's impartiality. ${ }^{47}$

Does a financial stake (such as ownership of a platform, or investment in a service from a particular platform) that could influence the recommendation of a particular platform constitute a conflict of interest? We buy flip charts and we use flip charts to brainstorm in face-to-face sessions. Is that the same as paying a yearly service fee to an online provider and pushing that platform to the clients as a good way to conduct sessions? Doctors who have invested in MRI equipment and who refer patients to use that MRI equipment are generally not seen to be in violation of ethical guidelines, but they assume liability in the event that harm is done to the patient. Does the investment in and use of an ODR platform bring similar liability to the conflict engagement practitioner? If I, as a third party, have parties use a platform that is then compromised and their personal information exposed, am I liable for legal action from the parties? At some point, one of these examples will surface in practice somewhere, and the outcome of the litigation will establish an answer post facto.

The use of technology creates possibilities that break through the boundaries that currently define the practice of conflict engagement. For example, it is possible, when using ODR platforms, to store and analyse data drawn from individual cases handled on the platforms. This makes it possible to describe trends in the creation of disputes, and trends in the resolution of disputes. The obvious advantage is that algorithms can be created to handle repeating disputes, as has been the approach for most e-commerce organizations. But it could also mean that third parties could have access to the 'most likely' resolutions for certain kinds of disputes, and could carry that knowledge into resolution sessions. Is this an appropriate use of the data that is created by the use of online platforms? Is gathering and using this type of data different from the gathering and use of user data that is currently the focus of many commercial online organizations?

Finally, there are questions about the ethics of the fourth party. ODR applications do not spring into being spontaneously - they are created by designers and 
programmers to specifications addressing the needs of conflict engagement practitioners. As Rainey and Abdul-Hadi Jadallah noted, '[...] the fourth party brings cultural assumptions and biases to the table just like any other party'. ${ }^{48}$ The decisions made by the designers and the programmers have a direct impact on accessibility and many other elements of the conflict engagement environment. Is it necessary to establish a separate code of ethics for ODR developers? The National Center for Technology and Dispute Resolution Fellows developed a set of standards for ODR development that include accessibility, affordability, transparency and fairness, ${ }^{49}$ but there are no 'binding' rules to govern the development of ODR applications. Whether there should be has not been a topic of open conversation at any of the professional organizations whose membership would be the users of the ODR platforms.

\section{Conclusion}

As a way to sum up the state of ethics and technology, as third parties we are at our most 'dangerous' - most likely to make mistakes and engage in inappropriate behaviour - when we take for granted our own expertise.

A healthy dose of insecurity is not a bad thing for a third party. Questioning one's initial impulses and probing to see if what you want to do, or what you do by default, is the right thing to do for the parties in a particular situation is a prudent ethical self-check. This is especially true when the use of ODR technology is involved.

Technology-assisted dispute resolution, be it mediation or some other form, is not just an analogue of a face-to-face process. There are changes in the nature of the interaction and the skills needed to manage communication and information exchange, all of which may have an impact on the parties with whom we work. That ODR is not merely an analogue of offline dispute resolution was reinforced by work on a U.S. NSF grant in the early 2000s. The project sought to create a definitive description of the offline mediation process, a description that could then be used to create an online platform built around the precise description of the offline mediation process. One of the most interesting early realizations, at least for the author, was that taking a well-defined offline process (mediation) into an online environment actually created something new - an online process that looked on the surface like the offline process but that was subtly and significantly changed during the transition. ${ }^{50}$

Not harming the parties is the aim of creating ethical standards, so if we are going to use technology (which we all do to some degree) it is incumbent upon us as practitioners to understand what technology is out there, how to use it, how to explain it and how to manage it.

48 D. Rainey \& A. Abdul-Hadi Jadallah, 'The Culture in the Code', International ODR Forum, Cairo, 2009, available at: <www.mediate.com//articles/culture_in_code.cfm>.

49 Available at: <www.icann.org/en/help/ombudsman/odr-standards-of-practice>.

50 National Science Foundation Grant Number 0429297, 2004-2007, 'Process Technology for Achieving Government Online Dispute Resolution'. 
Daniel Rainey

A good start would be to formally examine each of our accepted standards of practice, updating and revising them to take into account the impact of the fourth party. 